\title{
Stability-Indicating Photochemical Method for the Assay of Thiamine by Spectrophotometry
}

\author{
Iqbal Ahmad (D), ${ }^{1}$ Syed Haider Abbas, ${ }^{1}$ Zubair Anwar $\left(\mathbb{D},{ }^{1}\right.$ Muhammad Ali Sheraz $\left(\mathbb{D},{ }^{1}\right.$ \\ Sofia Ahmed (D), ${ }^{1}$ Muhammad Furqan Mobeen, ${ }^{2}$ Nafeesa Mustaan ${ }^{(D)},{ }^{1}$ and Wajiha Gul ${ }^{3}$ \\ ${ }^{1}$ Baqai Institute of Pharmaceutical Sciences, Baqai Medical University, Toll Plaza, Super Highway, Gadap Road, \\ Karachi 74600, Pakistan \\ ${ }^{2}$ Pharmatec Pakistan (Pvt.) Ltd., D-86/A S.I.T.E., Karachi, Pakistan \\ ${ }^{3}$ Department of Pharmaceutical Chemistry, Dow College of Pharmacy, Dow University of Health Sciences, \\ Ojha Campus, Karachi 74200, Pakistan \\ Correspondence should be addressed to Sofia Ahmed; sofia.ahmed@baqai.edu.pk
}

Received 13 February 2018; Revised 26 March 2018; Accepted 17 April 2018; Published 15 May 2018

Academic Editor: Rizwan Hasan Khan

Copyright (c) 2018 Iqbal Ahmad et al. This is an open access article distributed under the Creative Commons Attribution License, which permits unrestricted use, distribution, and reproduction in any medium, provided the original work is properly cited.

\begin{abstract}
A stability-indicating photochemical method has been developed for the assay of thiamine (TH) salts in aqueous solution and in fresh and aged vitamin preparations. It is based on the photooxidation of TH by UV irradiation to form thiochrome (TC) in alkaline solution. The TC: TH ratio under controlled conditions of light intensity, temperature, $\mathrm{pH}$, exposure time, and irradiation distance is constant and can be used to determine the concentration of UV irradiated TH solutions. TC, on extraction with isobutanol from the photodegraded solution of $\mathrm{TH}$, has been determined by the UV spectrophotometric method at $370 \mathrm{~nm}$. It exhibits a high intensity of absorption in the UV region that can be used for the assay of even low concentrations of TH. Under optimum conditions, Beer's law is obeyed in the concentration range of $0.20-2.00 \mathrm{mg} / 100 \mathrm{ml}\left(R^{2}=09998\right)$. The limit of detection (LOD) and limit of quantification (LOQ) are 0.0076 and $0.0231 \mathrm{mg} / 100 \mathrm{ml}$, respectively. The method has been validated and applied to aqueous solutions and vitamin preparations. The results have statistically been compared with the United States Pharmacopeia liquid chromatography method. It has been found that there is no significant difference between the two methods at $95 \%$ confidence level.
\end{abstract}

\section{Introduction}

Thiamine (vitamin $\left.\mathrm{B}_{1}\right)(\mathrm{TH})$ is a water-soluble vitamin and is used in the prevention and cure of the disease beriberi [1]. It is extensively used as a component of single vitamin B complex and multivitamin preparations [2-4]. Several analytical methods, including UV and visible spectrophotometric and multivariate analysis [5-7], fluorimetric [8-21], high performance liquid chromatography (HPLC) [22-35], UHPLC/MSMS [36], turbidimetric and nephelometric [37], amperometric [38], and voltammetric methods [39-45], have been used for the assay of thiamine and its salts in pharmaceutical preparations, food materials and biological fluids. Some of these methods have previously been reviewed [46-49]. A flow injection analysis- (FIA-) spectrophotometric method for the determination of TH after UV irradiation, based on difference spectrophotometry, has been reported [50]. The official methods for the assay of thiamine salts are based on nonaqueous titration [2] and liquid chromatography [3]. Thiamine undergoes chemical $[1,8,9,11,14,16,17,19,51-54]$ and photochemical oxidation $[55,56]$ to form thiochrome (TC) which exhibits a blue fluorescence $(440 \mathrm{~nm})$. This has been made as the basis of fluorimetric determination of $\mathrm{TH}$ $[8,9,11,14,16,17,19,54-60]$. The photochemical dehydrogenation of $\mathrm{TH}$ (1) to TC (3) probably proceeds through an intermediate (2) [52] as shown in Figure 1. The formation of TC is pH-dependent, and its yield is maximum at $\mathrm{pH} 10$ [52]. TC exhibits strong absorption in aqueous solution in the UV region [61].

The objective of this study is to develop and validate a simple, economical, and stability-indicating photochemical method for the assay of $\mathrm{TH}$ on the basis of the formation 
<smiles></smiles>

(1)<smiles>CC1=C(CCO)SC(C)N1Cc1cnc(C)nc1N</smiles>

$\mathrm{OH}$<smiles>CC1=C(CCO)SC2=Nc3nc(C)ncc3CN21</smiles>

(3)

Figure 1: Photochemical dehydrogenation of thiamine (1) to thiochrome (3).

of TC, its spectrophotometric determination, and to establish conditions for its quantitative relationship with $\mathrm{TH}$. The method would be applied to the assay of $\mathrm{TH}$ in pure solutions and in vitamin preparations.

\section{Experimental}

2.1. Materials. Thiamine hydrochloride (TH) and thiocrome (TC) were purchased from Sigma-Aldrich (USA). All reagents and solvents were of the purest form available from Merck (Germany). The buffer systems used were $\mathrm{Na}_{2} \mathrm{~B}_{4} \mathrm{O}_{7^{-}}$ $\mathrm{NaOH}(\mathrm{pH} 9-10)$ and $\mathrm{Na}_{2} \mathrm{HPO}_{4}-\mathrm{NaOH}(\mathrm{pH} \mathrm{11)}$; the ionic strength was maintained at $0.002 \mathrm{M}$.

2.2. Precautions. The experimental work was carried out in a dark chamber under subdued light. The TH solutions were protected from light to avoid the effect of any photochemical change before UV irradiation.

2.3. Photooxidation of $T H$. Aqueous solutions containing $4 \mathrm{mg} / 100 \mathrm{ml}$ of $\mathrm{TH}$ were prepared at $\mathrm{pH} 9-11$ using appropriate buffers with the addition of $2 \mathrm{ml}$ of a $30 \% \mathrm{H}_{2} \mathrm{O}_{2}$ solution. A $50 \mathrm{ml}$ quantity of the solution spread in a Petri dish was placed in a thermostat bath at $25 \pm 1^{\circ} \mathrm{C}$ and irradiated using a Philips $36 \mathrm{~W}$ TUV tube $(100 \%$ emission at $254 \mathrm{~nm}$ ) for $30 \mathrm{~min}$. The tube was fixed horizontally at a distance of $25 \mathrm{~cm}$ from the centre of the Petri dish in a radiation chamber. Samples were withdrawn at appropriate intervals and subjected to chromatographic examination and spectrophotometric assay.

2.4. Thin-Layer Chromatography (TLC). The formation of TC in UV irradiated solutions of TH was confirmed by TLC using $250 \mu \mathrm{m}$ silica gel $\mathrm{GF}_{254}$ plates and solvent system: (a) pyridine-isobutanol-water $(66: 17: 17, \mathrm{v} / \mathrm{v})$ and (b) 1-butanol-acetic acid-water (40:10:50, v/v, organic layer) [62].

The compounds were detected on comparison of their $R_{\mathrm{f}}$ values and fluorescence colour under $365 \mathrm{~nm}$ (TC, blue) and fluorescence quenching under $254 \mathrm{~nm}$ excitation (TH, dark), with those of the reference standards.

2.5. $p H$ Measurements. The $\mathrm{pH}$ of TH solutions was measured on an Elmetron LCD display pH meter (Model CP 501, sensitivity $\pm 0.01 \mathrm{pH}$ units, Poland) using a combination $\mathrm{pH}$ electrode. The calibration of the electrode was carried out using commercially available buffer tablets of $\mathrm{pH} 7$ and 9 (Merck).

2.6. Spectral Measurements. The spectral measurements on $\mathrm{TH}$ and TC solutions were performed on a Thermo Fisher Scientific UV-Vis spectrophotometer (Evolution 201, USA) using quartz cells of $10 \mathrm{~mm}$ path length.

2.7. Light Intensity Measurement. The intensity of the Philips $36 \mathrm{~W}$ TUV tube was determined by potassium ferrioxalate actinometry [63], and a value of $5.50 \pm 0.11 \times 10^{18}$ quanta $\mathrm{s}^{-1}$ was obtained.

\subsection{Spectrophotometric Assay of $\mathrm{TH}$}

2.8.1. Extraction of TC. A $5 \mathrm{ml}$ aliquot of the photooxidized solution of TH was placed in a $100 \mathrm{ml}$ separating funnel, $2 \mathrm{ml}$ of dehydrated ethanol was added, and the solution extracted with $10 \mathrm{ml}$ of isobutanol to isolate TC. The isobutanol layer was dried over $\mathrm{Na}_{2} \mathrm{SO}_{4}$ and used for the determination of the concentration of $\mathrm{TC}$ in the solution at $370 \mathrm{~nm}$ using $20,400 \mathrm{M}^{-1} \cdot \mathrm{cm}^{-1}$ as the value of molar absorptivity [61] or 654 as the value of $A(1 \% 1 \mathrm{~cm})$ at that wavelength. The same procedure was used for the determination of the concentration of TC in diluted solutions of photooxidized vitamin preparations.

2.8.2. Determination of TC:TH Ratios. The TC: TH ratios are determined by the formation of a certain amount of TC on the photooxidation of a fixed amount of $\mathrm{TH}$ under controlled experimental conditions (i.e., concentration of $\mathrm{TH}$, concentration of oxidizing agent, $\mathrm{pH}$ of the solution, irradiation source, and irradiation time). These values are determined from the concentrations of TC and TH and have been used for the assay of $\mathrm{TH}$ in different samples.

2.8.3. Assay of $T H$. The spectrophotometric assay of $\mathrm{TH}$ in pure solutions and in vitamin preparations has been carried 
TABLE 1: $R_{\mathrm{f}}$ values of thiamine $\mathrm{HCl}(\mathrm{TH})$ and thiochrome (TC).

\begin{tabular}{lcc}
\hline Compound & \multicolumn{3}{c}{ Solvent system } \\
& $a$ & $b$ \\
\hline TH & 0.03 & 0.27 \\
TC & 0.97 & 0.52 \\
\hline
\end{tabular}

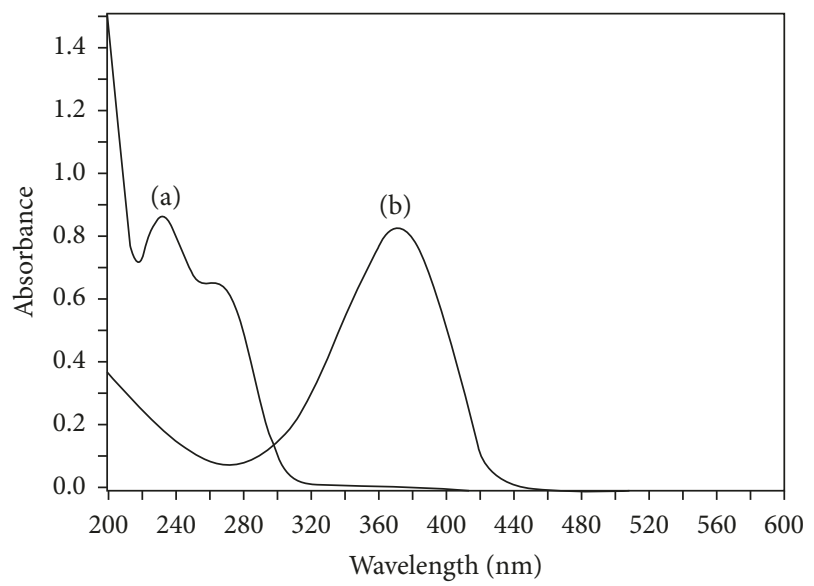

Figure 2: Absorption spectra of (a) thiamine $\mathrm{HCl}$ and (b) thiochrome, at $\mathrm{pH} 7.0$.

out on the basis of the $\mathrm{TC}: \mathrm{TH}$ ratios determined under controlled conditions as described in the above section. For example, if the TC: TH ratio obtained on the irradiation of a vitamin preparation containing $30 \mathrm{mg} \mathrm{TH}$ per $100 \mathrm{ml}$ is $0.405: 1$, the corresponding $\mathrm{TH}$ concentration can be calculated by the following formula:

$$
\begin{aligned}
& =\frac{1.600}{0.405} \times 7.5, \\
& =\frac{29.7 \mathrm{mg}}{100 \mathrm{ml}} .
\end{aligned}
$$$$
\mathrm{TH}=\frac{\text { amount of } \mathrm{TC} \text { formed }}{\mathrm{TC}: \mathrm{TH} \text { ratio }}
$$$$
\times \text { dilution factor of vitamin preparation, }
$$

\section{Results and Discussion}

3.1. Identification of Photoproduct of TH. The photooxidation of TH in alkaline solution leads to the formation of TC. The identification of TC in UV irradiated solutions of TH at pH 9-11 has been carried out by TLC using the solvent systems (a) and (b) (Section 2.4). TC was detected by comparison of its characteristic fluorescence (blue) and $R_{\mathrm{f}}$ values with those of the authentic compounds (Table 1). TC was only detected in $\mathrm{TH}$ solutions irradiated at $\mathrm{pH}$ 9-11 since it is known to be formed by photooxidation in alkaline solution [52]. Judging from the intensity of the fluorescence of $\mathrm{TC}$ in the $\mathrm{pH}$ range studied, the maximum yield was found for the reactions carried out at $\mathrm{pH} 10$.
TABLE 2: Analytical parameters for the assay of thiochrome (TC). $\lambda_{\max }$ Linearity $^{\mathrm{a}}$

Concentration range

Correlation coefficient

$370 \mathrm{~nm}$

Slope

SE of slope

Intercept

$0.20-2.00 \mathrm{mg} \%$

0.9999

654

0.0048

0.0031

SE of intercept

0.00325

SD of intercept

Recovery range (\%)

0.0103

Accuracy $(\%)^{\mathrm{b}} \pm \mathrm{SD}$

$99.3-100.7$

Precision $(\% \mathrm{RSD})^{\mathrm{c}}$

$99.71 \pm 0.50$

$\mathrm{LOD}^{\mathrm{d}}(\mathrm{mg})$

0.50

0.052

$\mathrm{LOQ}^{\mathrm{e}}(\mathrm{mg})$

0.157

${ }^{\mathrm{a}}$ Linearity, $n=5 .{ }^{\mathrm{b}}$ Accuracy, $n=6$ at $100 \%$ concentration. ${ }^{\mathrm{c}}$ Precision, $n=6$ at $100 \%$ concentration. ${ }^{\mathrm{d}} \mathrm{Limit}$ of detection $(\mathrm{LOD})=3.3 \times \sigma / \mathrm{S}$, where $\sigma$ is the standard deviation and $S$ is the slope of the standard curve. ${ }^{\mathrm{e}}$ Limit of quantitation $(\mathrm{LOQ})=10 \times \sigma / S$, where $\sigma$ is the standard deviation and $S$ is the slope of the standard curve.

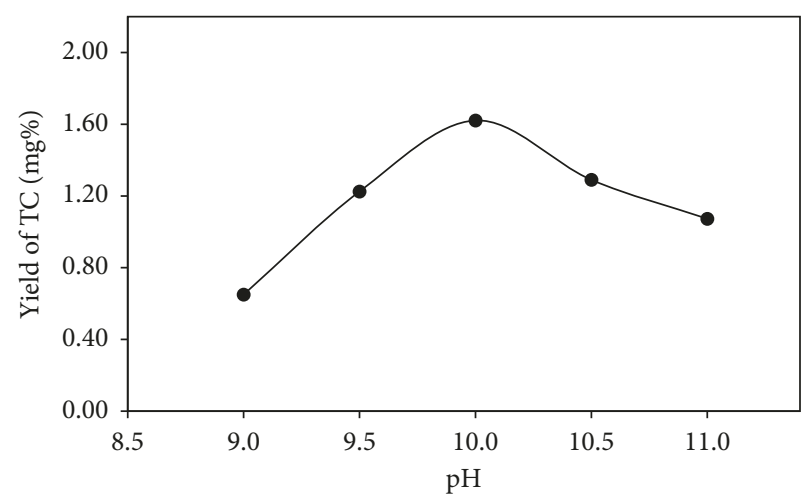

FIgURE 3: Yield of TC as a function of reaction $\mathrm{pH}$.

3.2. Spectral Characteristics of $\mathrm{TH}$ and TC. $\mathrm{TH}$ exhibits absorption maximum at $\mathrm{pH} 7$ at $246 \mathrm{~nm}$ with a molar absorptivity value of $15,200 \mathrm{M}^{-1} \cdot \mathrm{cm}^{-1}$ and an $\mathrm{A}(1 \% 1 \mathrm{~cm})$ value of 450 [64]. TC shows an absorption maximum at $370 \mathrm{~nm}$ with a molar absorptivity of $20,400 \mathrm{M}^{-1} \cdot \mathrm{cm}^{-1}$ [61] and an $\mathrm{A}(1 \% 1 \mathrm{~cm})$ value of 654 (Figure 2). In the present study, a molar absorptivity value of $19,800 \mathrm{M}^{-1} \cdot \mathrm{cm}^{-1}$ and an A $(1 \%, 1 \mathrm{~cm})$ value of 635 for TC at $370 \mathrm{~nm}$ have been obtained (Table 2). In view of the very high value of the molar absorptivity of TC at $370 \mathrm{~nm}$, it can be conveniently used for the assay of $\mathrm{TH}$ in vitamin preparations on its photooxidation to TC under controlled conditions as described in Section 3.5. The absorption maximum of TC at $370 \mathrm{~nm}$ provides maximum specificity and sensitivity for absorbance measurements in the method. The validation data for the test method is reported in Table 2.

3.3. Yield of TC. The photooxidation reaction of $\mathrm{TH}$ has been carried out at $\mathrm{pH} 9-11$. It has been observed that the yield of TC on UV irradiation for a fixed period of time is maximum at $\mathrm{pH} 10$ compared to that of $\mathrm{pH} 9$ and 11 (Figure 3). Therefore, $\mathrm{pH} 10$ was considered suitable for the photooxidation reaction of $\mathrm{TH}$ under the conditions used in this 
TABle 3: TC: TH ratios for UV irradiated TH solutions (4 mg \%) at $\mathrm{pH}$ 9.0-11.0.

\begin{tabular}{|c|c|c|c|c|c|}
\hline $\mathrm{pH}$ & TH concentration (mg \%) & Time $(\min )$ & $A_{370 \mathrm{~nm}}$ & TC concentration $(\mathrm{mg} \%)^{\mathrm{a}}$ & TC: TH ratio \\
\hline \multirow{3}{*}{9.0} & & 0 & 0 & 0 & - \\
\hline & 4.0 & 15 & 0.221 & 0.334 & $0.084: 1$ \\
\hline & & 30 & 0.425 & 0.650 & $0.162: 1$ \\
\hline \multirow{3}{*}{10.0} & & 0 & 0 & 0 & - \\
\hline & 4.0 & 15 & 0.512 & 0.782 & $0.196: 1$ \\
\hline & & 30 & 1.06 & 1.621 & $0.405: 1$ (optimum value) \\
\hline \multirow{3}{*}{11.0} & & 0 & 0 & 0 & - \\
\hline & 4.0 & 15 & 0.411 & 0.628 & $0.157: 1$ \\
\hline & & 30 & 0.702 & 1.073 & $0.268: 1$ \\
\hline
\end{tabular}

a The concentration of TC in photooxidized solution of TH has been calculated from the increase in absorbance at $370 \mathrm{~nm}$ of the extracted solution at $30 \mathrm{~min}$ irradiation using 654 as the value of $A(1 \% 1 \mathrm{~cm})$ [61].

TABle 4: Assay of $\mathrm{TH}$ in vitamin preparations $\left(25 \pm 1^{\circ} \mathrm{C}\right)$.

\begin{tabular}{|c|c|c|c|c|c|c|c|}
\hline \multirow{3}{*}{ Method } & \multirow{3}{*}{$\begin{array}{l}\text { Labeled }^{\mathrm{a}} \\
(\mathrm{mg} / 100 \mathrm{ml})\end{array}$} & \multicolumn{6}{|c|}{ Vitamin preparations stored in original package (pH 3-4) } \\
\hline & & \multicolumn{3}{|c|}{ Fresh } & \multicolumn{3}{|c|}{ Aged (6 months) } \\
\hline & & $\begin{array}{c}\text { Found }^{\mathrm{b}} \\
(\mathrm{mg} / 100 \mathrm{ml})\end{array}$ & Recovery $^{\mathrm{c}}(\%)$ & RSD (\%) & $\begin{array}{c}\text { Found } \\
(\mathrm{mg} / 100 \mathrm{ml})\end{array}$ & Recovery (\%) & RSD (\%) \\
\hline \multicolumn{8}{|c|}{ USP LC method } \\
\hline Sample 1 & 30 & 30.2 & 100.7 & 1.7 & 28.8 & 96.0 & 1.6 \\
\hline Sample 2 & 50 & 49.8 & 99.6 & 1.9 & 46.5 & 93.0 & 1.8 \\
\hline Sample 3 & 83 & 83.6 & 100.7 & 1.6 & 78.5 & 94.6 & 1.7 \\
\hline \multicolumn{8}{|c|}{ Proposed method } \\
\hline Sample 1 & 30 & 30.0 & 100.0 & 1.2 & 27.5 & 91.7 & 1.6 \\
\hline Sample 2 & 50 & 48.2 & 98.6 & 1.4 & 45.9 & 91.8 & 1.5 \\
\hline Sample 3 & 83 & 82.5 & 99.4 & 1.7 & 73.6 & 88.6 & 1.8 \\
\hline
\end{tabular}

study (Table 3). It has earlier been reported that the formation of TC depends on the $\mathrm{pH}$ of the medium, and its yield is maximum at $\mathrm{pH} 10$ [52]. Above $\mathrm{pH} 10, \mathrm{TH}$ is ionized to the negatively charged thiol form ( $\mathrm{p} K_{\mathrm{a}}$ 11.6) which undergoes hydrolytic degradation to thiazole and pyrimidine moieties [53]. Therefore, there is a decrease in the formation of $\mathrm{TC}$ with an increase in $\mathrm{pH}$ above 10.

3.4. Application of the Assay Method. The photochemical method has been applied to the assay of TH in fresh and aged pharmaceutical vitamin preparations, and the results are compared with the United States Pharmacopeia liquid chromatography method (Table 4). At 95\% confidence level, it has been found that the calculated $t$ value for each concentration is less than the tabulated $t$ value, indicating no significant difference between the two methods. The accuracy and precision of the method has been determined, and its sensitivity has been calculated (Table 2). The method is stability-indicating for the assay of $\mathrm{TH}$ in vitamin preparations on the basis of the amount of TC photochemically formed under controlled conditions and its quantitative relationship with $\mathrm{TH}$, that is, $\mathrm{TC}: \mathrm{TH}$ ratio. A similar photochemical method for the assay of riboflavin (RF) on the basis of the formation of its photoproduct, lumichrome (LC) and LC: RF ratio, has been reported [65].

\subsection{Experimental Conditions}

3.5.1. Radiation Source. A 36 W TUV tube (100\% emission at $254 \mathrm{~nm}$ ) has been found to be suitable for the photooxidation of $\mathrm{TH}$. The absorption maximum of $\mathrm{TH}(246 \mathrm{~nm})$ [64] overlaps the emission band of the TUV tube that provides maximum radiation energy for the photochemical reaction and the formation of TC.

3.5.2. Radiation Source-Vessel Distance. The distance between the radiation source and the reaction vessel must be constant for a fixed number of quanta to be absorbed to perform a uniform photochemical reaction. A distance of $25 \mathrm{~cm}$ between the radiation source and the reaction vessel has been found to be appropriate for this work.

3.5.3. Temperature. The control of temperature is essential for photochemical studies to avoid any thermal effect on the rate of reaction. This has been achieved by irradiation of the solutions in a thermostat bath maintained at a constant temperature, that is, $25 \pm 1^{\circ} \mathrm{C}$ during the reaction.

3.5.4. Irradiation Time. The irradiation of the solutions for a fixed period of time is necessary to achieve uniform results 
in the formation of TC. In the present study, a time period of $30 \mathrm{~min}$ has been found to be sufficient to avoid any photodegradation of TC [52].

3.5.5. Oxidizing Agent. The oxidation of $\mathrm{TH}$ in alkaline solutions occurs in the presence of an oxidizing agent, that is, potassium ferricyanide [66] or hydrogen peroxide [67]. In the present study, the photooxidation of TH has been carried out in the presence of hydrogen peroxide to avoid any interference of the oxidizing agent in the absorbance of TC.

\section{Conclusion}

A simple photochemical method has been developed and validated for the assay of $\mathrm{TH}$ in aqueous solution and pharmaceutical vitamin preparations. It is based on the photooxidation of $\mathrm{TH}$ to $\mathrm{TC}$, determination of their quantitative relationship (TC: $\mathrm{TH}$ ratio) under controlled conditions and on this basis the assay of $\mathrm{TH}$ in different pharmaceutical samples. TC has a high value of A $(1 \%, 1 \mathrm{~cm})$ and can be conveniently determined by spectrophotometry at $370 \mathrm{~nm}$. The method is comparable to the United States Pharmacopeia method.

\section{Data Availability}

The data used to support the findings of this study are available from the corresponding author upon request.

\section{Conflicts of Interest}

The authors declare that they have no conflicts of interest.

\section{Acknowledgments}

The authors gratefully acknowledge the Higher Education Commission of Pakistan for financial support to conduct this study through an NRPU Grant (Research Project no. 20-3968) to Iqbal Ahmad.

\section{References}

[1] C. J. Bates, “Thiamine," in Handbook of Vitamins, Chapter 8 J. Zempleni, R. B. Rucker, D. B. McCormick, and J. W. Suttie, Eds., CRC Press, Boca Raton, FL, USA, 2007.

[2] British Pharmacopoeia, Monograph on Thiamine, Her Majesty's Stationary Office, London, UK, 2016.

[3] United States Pharmacopeia 29, Monograph on Thiamine, United States Pharmacopeial Convention, Rockville, MD, USA, 2016.

[4] S. C. Sweetman, Martindale: The Complete Drug Reference, Pharmaceutical Press, London, UK, 36th edition, 2009.

[5] S. T. Abdel Rehman, A. A. Elbashir, M. El-Mukhtar, and M. M. Ibrahim, "Application of spectrophotometric methods for the determination of thiamine (vb1) in pharmaceutical formulations using 7-chloro-4-nitrobenzoxadiazole (NBDCl)," Journal of Analytical \& Pharmaceutical Research, vol. 2, no. 3, p. 0018, 2016.

[6] P. L. Lopez-de-Alba, L. Lopez-Martinez, V. Cerda, and J. Amador-Hernandez, "Simultaneous determination and classification of riboflavin, thiamine, nicotinamide and pyridoxine in pharmaceutical formulations, by UV-visible spectrophotometry and multivariate analysis," Journal of Brazilian Chemical Society, vol. 17, no. 4, pp. 715-722, 2006.

[7] M. Abdel-Maaboud, M. Horria, M. A. Niveen, and E.-Z. Marwa, "Chemometric methods for the simultaneous determination of some water-soluble vitamins," Journal of AOAC International, vol. 94, no. 2, pp. 467-481, 2011.

[8] Q.-Y. Chen, D.-H. Li, H.-H. Yang, Q.-Z. Zhu, H. Zheng, and J.-G. $\mathrm{Xu}$, "Novel spectrofluorimetric method for the determination of thiamine with iron(iii) tetrasulfonatophthalocyanine as a catalyst," Analyst, vol. 124, no. 5, pp. 771-775, 1999.

[9] H. Zhu, H. Chen, and Y. Zhou, "Determination of thiamine in pharmaceutical preparations by sequential injection renewable surface solid-phase spectrofluorometry," Analytical Sciences, vol. 19, no. 2, pp. 289-294, 2003.

[10] A. Alonso, M. J. Almendral, M. J. Porras, and Y. Curto, "Flowinjection solvent extraction without phase separation. fluorimetric determination of thiamine by the thiochrome method," Journal of Pharmaceutical and Biomedical Analysis, vol. 42, no. 2, pp. 171-177, 2006.

[11] A. B. Tabrizi, "A cloud point extraction-spectrofluorimetric method for determination of thiamine in urine," Bulletin of Korean Chemical Society, vol. 27, no. 10, pp. 1604-1608, 2006.

[12] M. Amjadi, J. L. Manzoori, and M. Orooji, "The use of crude extract of kohlrabi (brassica oleracea gongylodes) as a source of peroxidase in the spectrofluorimetric determination of thiamine," Bulletin of Korean Chemical Society, vol. 28, no. 2, pp. 246-250, 2007.

[13] J. Sun, L. Liu, C. Ren, X. Chen, and Z. Hu, "A feasible method for the sensitive and selective determination of vitamin B1 with CdSe quantum dots," Microchimica Acta, vol. 163, no. 34, pp. 271-276, 2008.

[14] M. A. Khan, S. O. Jin, S. H. Lee, and H. Y. Chung, "Spectrofluorimetric determination of vitamin $\mathrm{B}_{1}$ using horseradish peroxidase as catalyst in the presence of hydrogen peroxide," Luminescence, vol. 24, no. 2, pp. 73-78, 2009.

[15] Y. Li, P. Wang, M. Cao et al., "An immediate luminescence enhancement method for determination of vitamin $B_{1}$ using long-wavelength emitting water-soluble CdTe nanorods," Microchimica Acta, vol. 169, no. 1-2, pp. 65-71, 2010.

[16] M. Zeeb, M. R. Ganjali, and P. Norouzi, "Dispersive liquidliquid microextraction followed by spectrofluorimetry as a simple and accurate technique for determination of thiamine (vitamin $\left.\mathrm{B}_{1}\right)$," Microchimica Acta, vol. 168, no. 3-4, pp. $317-324,2010$.

[17] A. M. Mohamed, H. A. Mohamed, N. M. Abdel-Latif, and M. R. Mohamed, "Spectrofluorimetric determination of some water-soluble vitamins," Journal of AOAC International, vol. 94, no. 6, pp. 1758-1769, 2011.

[18] G. D. Tarigh and F. Shemirani, "Simultaneous in situ derivatization and ultrasound-assisted dispersive magnetic solid phase extraction for thiamine determination by spectrofluorimetry," Talanta, vol. 123, pp. 71-77, 2014.

[19] J. Zhu, S. Liu, Z. Liu, Y. Liu, M. Qiao, and X. Hu, "Enhanced spectrofluorimetric determination of hypochlorite based on the catalytic oxidation of thiamine to thiochrome in the presence of trace ferrocyanide," RSC Advances, vol. 4, no. 12, pp. 5990-5994, 2014.

[20] H. Tan, Q. Li, Z. Zhou et al., “A sensitive fluorescent assay for thiamine based on metal-organic frameworks with intrinsic peroxidase-like activity," Analytica Chimica Acta, vol. 856, pp. 90-95, 2015. 
[21] Y. Luo, H. Miao, and X. Yang, "Glutathione-stabilized Cu nanoclusters as fluorescent probes for sensing $\mathrm{pH}$ and vitamin B $_{1}$," Talanta, vol. 144, pp. 488-495, 2015.

[22] X. Tang, D. A. Cronin, and N. P. Brunton, "A simplified approach to the determination of thiamine and riboflavin in meats using reverse phase HPLC," Journal of Food Composition and Analysis, vol. 19, no. 8, pp. 831-837, 2006.

[23] M. Ake, Y. N. Soko, and K. A. Malan, "Liquid chromatographic determination of free thiamine and its esters in whole blood," Dakar Medical, vol. 51, no. 3, pp. 172-177, 2006.

[24] A. Zafra-Gomez, A. Garballo, J. C. Morales, and L. E. Garcia-Ayuso, "Simultaneous determination of eight water-soluble vitamins in supplemented foods by liquid chromatography," Journal of Agriculture and Food Chemistry, vol. 54, no. 13, pp. 4531-4536, 2006.

[25] A. Lebiedzinska, M. L. Marszall, J. Kuta, and P. Szefer, "Reversed-phase high-performance liquid chromatography method with coulometric electrochemical and ultraviolet detection for the quantification of vitamins $\mathrm{B}(1)$ (thiamine), $\mathrm{B}(6)$ (pyridoxamine, pyridoxal and pyridoxine) and $\mathrm{B}(12)$ in animal and plant foods," Journal of Chromatography A, vol. 1173, no. 1-2, pp. 71-80, 2007.

[26] N. Yanith, D. Widowati, Wartini, and T. Aryani, "Validation of HPLC method for determination of thiamine hydrochloride, riboflavin, nicotinamide, and pyridoxine hydrochloride in syrup preparation," Canadian Journal on Scientific and Industrial Research, vol. 2, no. 7, pp. 269-278, 2011.

[27] X. X. Wang, Y. Hu, Y. Z. Sun, M. J. Bie, and C. J. Sun, "Simultaneous determination of five water-soluble vitamins in human serum by high performance liquid chromatography," Sichuan Da Xue Xue Bao Yi Xue Ban, Journal of Sichuan University, Medical Science Edition, vol. 41, no. 1, pp. 158-161, 2010.

[28] J. Tan, R. Li, and Z.-T. Jiang, "Determination of thiamine (vitamin $B_{1}$ ) in pharmaceutical tablets and human urine by titania-based ligand-exchange hydrophilic interaction chromatography," Analytical Methods, vol. 3, pp. 1568-1573, 2011.

[29] E. Dinc, G. Kokdil, and F. Onur, "A comparison of matrix resolution method, ratio spectra derivative spectrophotometry and HPLC method for the determination of thiamine $\mathrm{HCl}$ and pyridoxine $\mathrm{HCl}$ in pharmaceutical preparation," Journal of Pharmaceutical and Biomedical Analysis, vol. 22, no. 6, pp. 915-923, 2000.

[30] P. Jin, L. Xia, Z. Li, N. Che, D. Zou, and X. Hu, "Rapid determination of thiamine, riboflavin, niacinamide, pantothenic acid, pyridoxine, folic acid and ascorbic acid in vitamins with minerals tablets by high-performance liquid chromatography with diode array detector," Journal of Pharmaceutical and Biomedical Analysis, vol. 70, pp. 151-157, 2012.

[31] R. S. J. Rodriguez, V. Fernandez-Ruiz, M. Camara, and M. C. Sanchez-Mata, "Simultaneous determination of vitamin $\mathrm{B}_{1}$ and $\mathrm{B}_{2}$ in complex cereal foods, by reverse phase isocratic HPLC-UV," Journal of Cereal Science, vol. 55, no. 3, pp. 293-299, 2012.

[32] I. Marquez-Sillero, S. Cardenas, and M. Valcarcel, "Determination of water-soluble vitamins in infant milk and dietary supplement using a liquid chromatography on-line coupled to a corona-charged aerosol detector," Journal of Chromatography A, vol. 1313, pp. 253-258, 2013.

[33] T. Miyazaki, T. Hori, Y. Aso, and H. Okuda, "Ion-pair HPLC analysis of B vitamins in syrup products in Indonesia," Kokuritsu Iyakuhin Shokuhin Eisei Kenkyusho Hokoku,
Bulletin of National Institute of Health Sciences, vol. 131, pp. 58-65, 2013.

[34] N. Michlig, F. V. de Velde, M. R. Freyre, M. Cecilia, and H. Bernardi, "Determination of thiamine in wheat flours using a validated isocratic HPLC-fluorescence method previously optimized by box-behnken design," Food Analytical Methods, vol. 7, no. 4, pp. 828-835, 2014.

[35] B. Basiri, J. M. Sutton, B. S. Hanberry, J. A. Zastre, and M. G. Bartlett, "Ion pair liquid chromatography method for the determination of thiamine (vitamin B1) homeostasis," Biomedical Chromatography, vol. 30, no. 1, pp. 35-41, 2016.

[36] D. Hampel, E. R. York, and L. H. Allen, "Ultra-performance liquid chromatography tandem mass-spectrometry (UPLCMS/MS) for the rapid, simultaneous analysis of thiamin, riboflavin, flavin adenine dinucleotide, nicotinamide and pyridoxal in human milk," Journal of Chromatography B Analytical Technologies in the Biomedical and Life Sciences, vol. 903, pp. 7-13, 2012.

[37] V. B. Santos, T. B. Guerreiro, W. T. Suarez, R. C. Faria, and O. Fatibello-Filho, "Evaluation of turbidimetric and nephelometric techniques for analytical determination of $n$-acetylcysteine and thiamine in pharmaceutical formulations employing a lab-made portable microcontrolled turbidimeter and nephelometer," Journal of the Brazilian Chemical Society, vol. 22, no. 10, pp. 1968-1978, 2011.

[38] E. Akyilmaz, I. Yasa, and E. Dinckaya, "Whole cell immobilized amperometric biosensor based on Saccharomyces cerevisiae for selective determination of vitamin $\mathrm{B}_{1}$ (thiamine)," Analytical Biochemistry, vol. 354, no. 1, pp. 78-84, 2006.

[39] X. Jiang and T. Sun, "Indication ion square wave voltammetric determination of thiamine and ascorbic acid," Electrochemistry, vol. 40, no. 13, pp. 2589-2596, 2007.

[40] P. Norouzi, T. M. Garakani, H. Rashedi, H. A. Zamani, and M. R. Ganjali, "Ultrasensitive flow-injection electrochemical method using fast fourier transform square-wave voltammetry for detection of vitamin $\mathrm{B}_{1}$," International Journal of Electrochemical Science, vol. 5, pp. 639-652, 2010.

[41] B. Bas, M. Jakubowska, and L. Gorski, "Application of renewable silver amalgam annular band electrode to voltammetric determination of vitamins $\mathrm{C}, \mathrm{B}_{1}$ and $\mathrm{B}_{2}$," Talanta, vol. 84, no. 4, pp. 1032-1037, 2011.

[42] K. Tyszczuk-Rotko, "New voltammetric procedure for determination of thiamine in commercially available juices and pharmaceutical formulation using a lead film electrode," Food Chemistry, vol. 134, no. 2, pp. 1239-1243, 2012.

[43] P. K. Brahman, R. A. Dar, and K. S. Pitre, "DNAfunctionalized electrochemical biosensor for detection of vitamin B1 using electrochemically treated multiwalled carbon nanotube paste electrode by voltammetric methods," Sensors and Actuators B: Chemical, vol. 177, pp. 807-812, 2013.

[44] I. P. Antal, Y. R. Bazel, and Z. A. Kormosh, "Electrochemical methods for determining group B vitamins," Journal of Analytical Chemistry, vol. 68, no. 7, pp. 565-576, 2013.

[45] I. G. David, M.-A. Florea, O. G. Cracea et al., "Voltammetric determination of $\mathrm{B}_{1}$ and $\mathrm{B}_{6}$ vitamins using a pencil graphite electrode," Chemical Papers, vol. 69, no. 7, pp. 901-910, 2015.

[46] R. R. Eitenmiller and W. O. Landen Jr., "Thiamin," in Modern Analytical Methodologies in Fat-and Water-oluble Vitamins, Chapter 6, W. O. Song, G. R. Becker, and R. R. Eitenmiller, Eds., Wiley, New York, NY, USA, 2000. 
[47] G. F. M. Ball, "Thiamin," in Vitamins in Food Analysis, Bioavailability and Stability, Chapter 7, CRC Press, Boca Raton, FL, USA, 2006.

[48] R. R. Eitenmiller, L. Ye, and W. O. Landen Jr., "Thiamin," in Vitamin Analysis for the Health and Food Science, Chapter 6, CRC Press, Boca Raton, FL, USA, 2nd edition, 2008.

[49] C. J. Bates, Vitamins: Fat and Water Soluble: Analysis, Encyclopedia of Analytical Chemistry, R. A. Meyers, Ed., John Wiley, Chichester, UK, 2000.

[50] A. F. Danet and J. M. Calatayud, "FIA-spectrophotometric determination of thiamine after UV-irradiation," Talanta, vol. 41, no. 12, pp. 2147-2151, 1994.

[51] B. C. P. Jansen, "A chemical determination of aneurin (vitamin $\mathrm{B}_{1}$ ) by thiochrome reaction," Recueil des Travaux Chimiques des Pays-Bas, vol. 55, no. 12, pp. 1046-1052, 1936.

[52] H. R. Rosenberg, Chemistry and Physiology of the Vitamins, Interscience, New York, NY, USA, 1945.

[53] K. A. Connors, G. L. Amidon, and V. J. Stella, Monograph on Thiamine Hydrochloride, Chemical Stability of Pharmaceuticals: A Handbook for Pharmacist, John Wiley, New York, NY, USA, 1986.

[54] United States Pharmacopoeia Convention, United States Pharmacopeia 29-National Formulary 24, United States Pharmacopeial Convention, Inc., Rockville, MD, USA, 2006.

[55] Q. Guo, J.-G. Xu, Y.-Z. Wu, Y.-B. Zhao, X.-Z. Huang, and G.-Z. Chen, "Determination of thiamine (vitamin $B_{1}$ ) by in situ sensitized photochemical spectrofluorimetry," Analytica Chimica Acta, vol. 276, no. 1, pp. 151-160, 1993.

[56] A. Wasielczuk, M. Catala Icardo, J. V. Carcia Mateo, and J. Martinez Calatayud, "Flow-injection chemiluminescent determination of thiamine in pharmaceutical samples by online photodegradation," Analytical Letters, vol. 37, no. 15, pp. 3205-3218, 2004.

[57] D. F. Clausen and R. E. Brown, "Determination of thiamine by the thiochrome method. Effects of temperature and dissolved oxygen on fluorescence of quinine standard and of thiochrome," Industrial and Engineering Chemistry, vol. 16, no. 9, pp. 572-574, 1944.

[58] G. A. Leveille, "Modified thiochrome procedure for the determination of urinary thiamin," American Journal of Clinical Nutrition, vol. 25, no. 3, pp. 273-274, 1972.

[59] M. H. Dong, M. D. Green, and H. E. Sauberlich, "Determination of urinary thiamin by the thiochrome method," Clinical Biochemistry, vol. 14, no. 1, pp. 16-18, 1981.

[60] G. R. Skurray, "A rapid method for selectively determining small amount of niacin, riboflavin and thiamin in foods," Food Chemistry, vol. 7, no. 2, pp. 77-80, 1981.

[61] N. N. Bubeshko, V. I. Stsiapura, and I. I. Stepuro, "Fluorescent properties of thiochrome in solvents of different polarity," Journal of Applied Spectroscopy, vol. 78, p. 337, 2011.

[62] H. R. Bolliger and A. Konig, "Vitamin, including carotenoids, chlorophyll and biologically active quinones," in Thin-Layer Chromatography, E. Stahl, Ed., p.295, Springer, New York, NY, USA, 2nd edition, 1969.

[63] C. G. Hatchard and C. A. Parker, "A new sensitive chemical actinometer," Proceedings of Royal Society of London Series A, Mathematical and Physical Sciences, vol. 235, no. 1203, pp. 518-536, 1956.

[64] A. C. Moffat, M. D. Osselton, and D. Widdop, Clarke's Analysis of Drugs and Poisons in Pharmaceuticals, Body Fluids and Postmortem Material, Pharmaceutical Press, London, UK, 3rd edition, 2004.

[65] I. Ahmad, S. H. Abbas, Z. Anwar et al., "Stability-indicating photochemical method for the assay of riboflavin: lumichrome method," Journal of Chemistry, vol. 2015, Article ID 256087, 8 pages, 2015.

[66] G. Barger, F. Bergel, and A. R. Todd, "A crystalline fluorescent dehydrogenation product from vitamin $\mathrm{B}_{1}$," Nature, vol. 136, no. 3433 , p. $259,1935$.

[67] H. N. Haugen, "The determination of thiamine by the thiochrome method," Scandinavian Journal of Clinical and Laboratory Investigation, vol. 12, no. 3, pp. 253-260, 1960. 

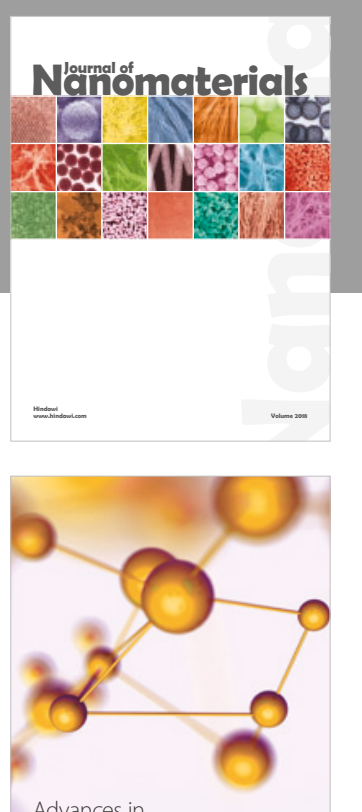

Physical Chemistry
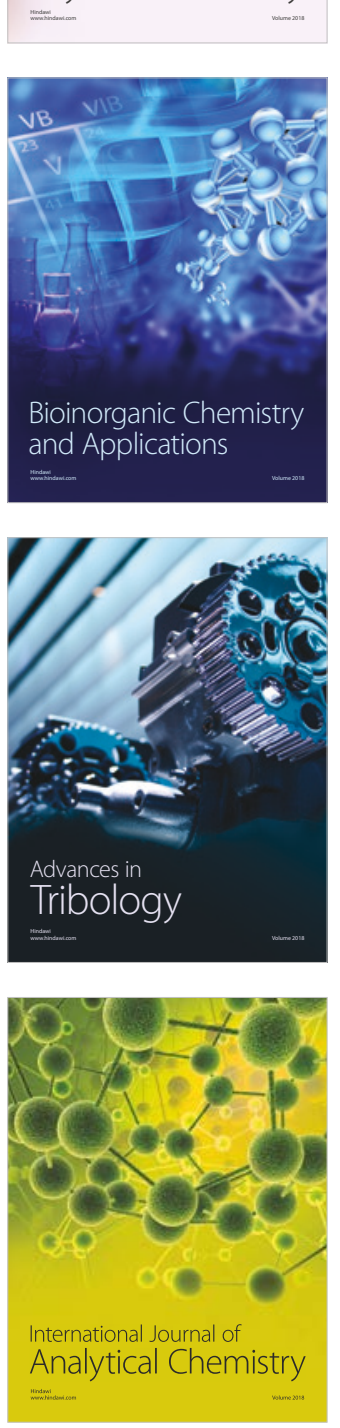

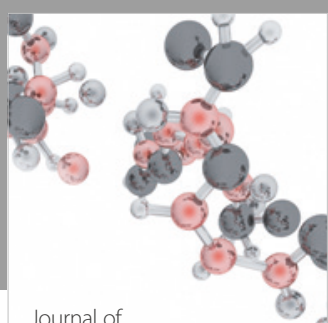

Analytical Methods

in Chemistry

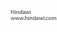

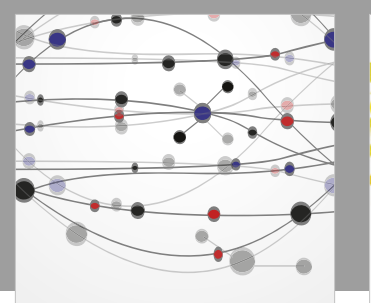

The Scientific World Journal

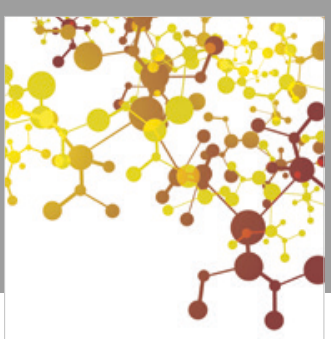

Journal of

Applied Chemistry
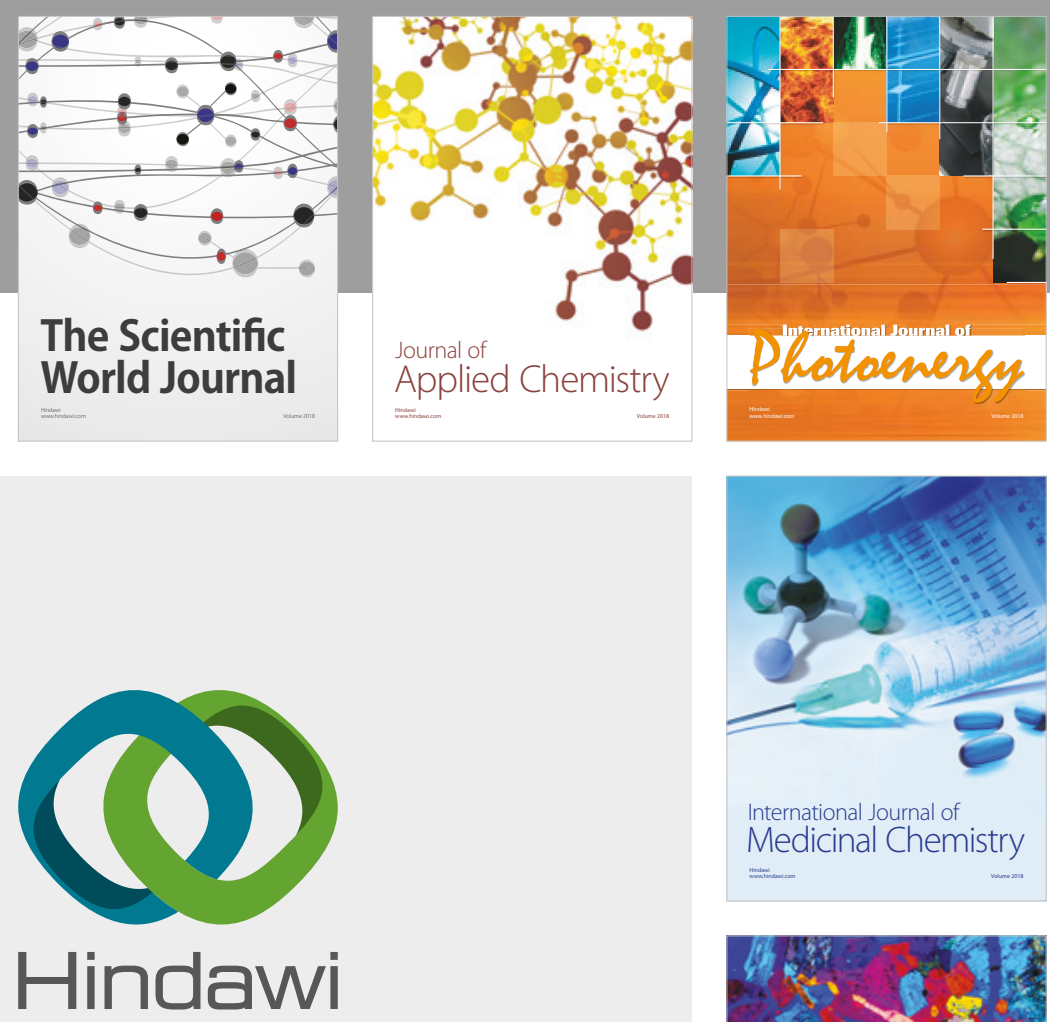

Submit your manuscripts at

www.hindawi.com
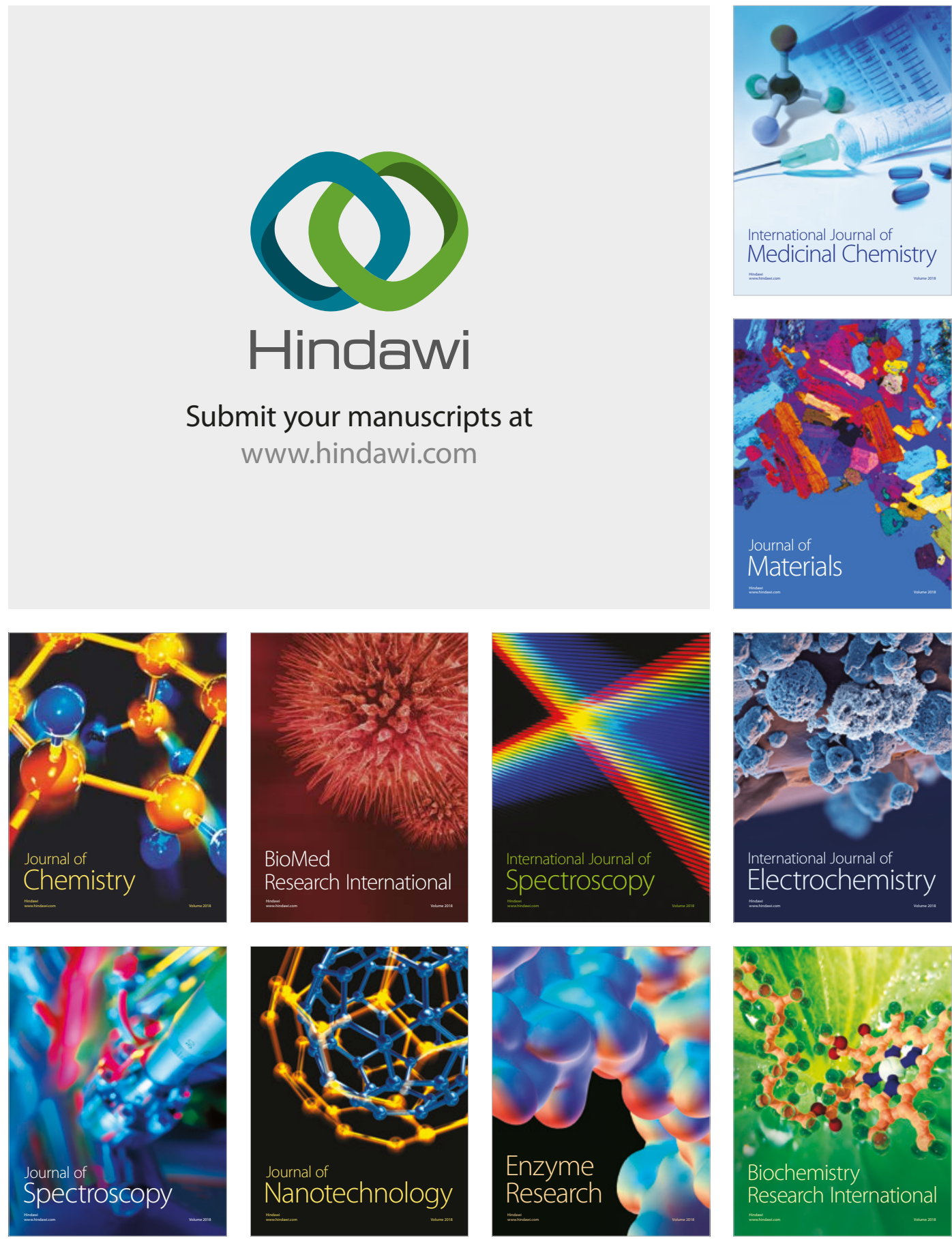
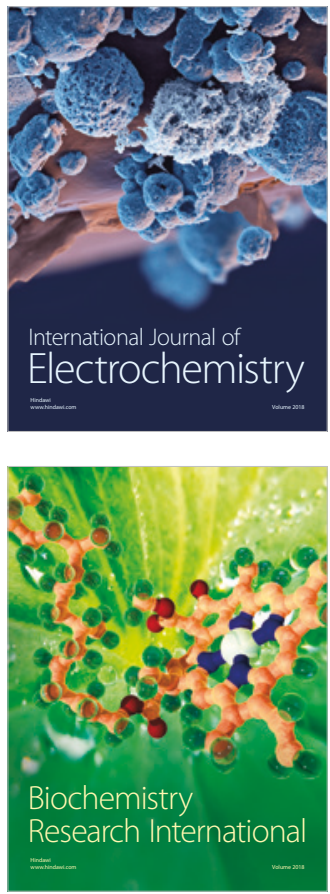